\title{
The Role of Ultrasound in the Diagnosis and Management of Trophoblastic Diseases (TMD) at the University Teaching Hospital Yalgado Ouedraogo (UTH-YO) of Ouagadougou
}

\author{
Ouattara Adama ${ }^{1,2 *}$, Ouedraogo Nde Nina Astridd,2, Lankoandé Bako Natacha ${ }^{3}$, \\ Tougma Sanou Aline ${ }^{3}$, Sawadogo Yobi Alexis ${ }^{1,2}$, Millogo Traoré Francoise ${ }^{1,2}$, \\ Ouédraogo Marie Charlemagne ${ }^{1,2}$, Ouédraogo Ali1,2, Thieba Bonané Blandine ${ }^{1,2}$
}

\begin{abstract}
${ }^{1}$ Training and Research Unit in Health Sciences (TRU/HS), University Ouaga 1 Pr Joseph KI ZERBO, Ouagadougou, Burkina Faso ${ }^{2}$ Department of Gynecology and Obstetrics, The University Teaching Hospital Yalgado Ouedraogo of Ouagadougou (UTH-YO), Ouagadougou, Burkina Faso

${ }^{3}$ Department of Gynecology and Obstetrics, The Bogodogo University Teaching Hospital of Ouagadougou (UTH-B), Ouagadougou, Burkina Faso

Email: *ouattzangaadama@yahoo.fr
\end{abstract}

How to cite this paper: Adama, O., Astrid, O.N.N., Natacha, L.B., Aline, T.S., Alexis, S.Y., Francoise, M.T., Charlemagne, O.M., Ali, O. and Blandine, T.B. (2018) The Role of Ultrasound in the Diagnosis and Management of Trophoblastic Diseases (TMD) at the University Teaching Hospital Yalgado Ouedraogo (UTH-YO) of Ouagadougou. Open Journal of Obstetrics and Gynecology, 8, 1376-1388.

https://doi.org/10.4236/ojog.2018.813139

Received: October 6, 2018

Accepted: November 9, 2018

Published: November 12, 2018

Copyright $\odot 2018$ by authors and Scientific Research Publishing Inc. This work is licensed under the Creative Commons Attribution International License (CC BY 4.0).

http://creativecommons.org/licenses/by/4.0/

(c) (i) Open Access

\begin{abstract}
Objective: To describe the place of ultrasound in the diagnosis and management of Gestational Trophoblastic Diseases (GTD) at the Ouagadougou UTH-YO, Ouagadougou, Burkina Faso. Materials and Patients: It was a prospective and descriptive study over a 3-year period from 1 January 2015 to 31 December 2017. It took place in the gynecology and obstetrics department of at the University Teaching Hospital Yalgado Ouedraogo (UTH-YO) of Ouagadougou. Monitoring was based on clinical examination data, ultrasound and kinetics of $\beta$-gestational chorionic hormone (GCH) levels. Results: During the study period, we recorded 34 cases of trophoblastic diseases. The average age of the patients was 35 years with extremes of 22 and 52 years. Physical examination revealed a uterus larger than gestational age in 17 patients (56.67\%) of cases. Eight (26.67\%) patients were asymptomatic. The initial mean $\beta-\mathrm{GCH}$ was $453,747.8 \mathrm{IU} / \mathrm{l}$ with extremes of $5903 \mathrm{IU} / 1$ and 1,890,000 IU/l. Ultrasound was used to evoke the diagnosis in 23 patients, that to say $76.67 \%$ of the cases. Ultrasound identified 10 complete mole cases, 20 partial mole cases. For the 3 cases of invasive mole, pelvic ultrasound revealed heterogeneous intrauterine multi-vesicular images. In a case of choriocarcinoma, ultrasound found an enlarged uterus with a poorly limited intracavitary heterogeneous fundic image. Conclusion: This short series shows the central role of ultrasound in the diagnosis and follow-up of gestational trophoblastic diseases. Indeed, the sen-
\end{abstract}


sitivity of ultrasound is excellent in the early diagnosis of complete moles. Ultrasonography remains a good examination choice for the diagnosis of gestational trophoblastic tumors despite their great polymorphism. The place of ultrasound in prognostic evaluation and treatment monitoring deserves to be studied by more important series.

\section{Keywords}

Gestational Trophoblastic Diseases (GTD), UTH-YO, Ultrasound

\section{Introduction}

Gestational trophoblastic diseases (GTD) constitute a real public health problem for African countries because of their high incidence, their evolutionary potential and the difficulties related to their diagnosis and management [1]. The incidence varies from country to country and sometimes exceeds 1 in 500 pregnancies [2]. In Burkina Faso, a national study in 1998 estimated it at 9.7 per 1000 pregnancies [1]. Diagnostic and management modalities were formerly based on clinical history and biological data. Currently, they largely include imaging including ultrasound and magnetic resonance imaging (MRI). Indeed, the advent of supra pubic and/or endovaginal pelvic ultrasound has enabled both rapid and early diagnosis and post-therapeutic follow-up of the hydatidiform mole [3] [4] [5]. Through this study, we propose to describe the place of ultrasound in the diagnosis and management of GTD at the Ouagadougou UTH-YO with a view to sharing experiences.

\section{Materials and Methods}

Our study took place in the gynecology and obstetrics department of at the University Teaching Hospital Yalgado Ouedraogo (UTH-YO) of Ouagadougou. It was a prospective and descriptive study over a 3-year period from 1 January 2015 to 31 December 2017. All histologically confirmed cases where diagnosis was based on imaging and kinetics of the $\beta \mathrm{GCH}$ rate were comprehensively included in the study. Patients were collected from outpatient, gynecological and obstetrical emergency records at the UHC-YO. We worked in collaboration with the anatomopathology department and the Medical Oncology Department respectively for histological diagnosis and complementary management. Magnetic resonance imaging examinations were performed by the radiology team at the Saint Camille medical centre in Ouagadougou. We chose to divide our patients into two groups according to the classification of the International Federation of Obstetrical Gynecologists (FIGO) in 2000 [5]. The first group (G1) included complete moles (MC) and partial moles (MP) and the second group (G2), invasive moles (MI), choriocarcinomas (CC) and placental site tumors. The variables studied were: patient age, number of procedures, parity, gestational age at diagnosis, obstetrical history, clinical call signs, ultrasound data and therapeutic 
conduct. Monitoring was based on clinical examination data, ultrasound and kinetics of $\beta$-gestational chorionic hormone (GCH) levels. The data were collected from the medical files using a collection form designed for this purpose and then computerised. They were entered and analyzed on the Epi Info software version 6.0. Pearson, Fisher and Student chi-square tests were used to compare the data. A p-value of less than 0.05 was considered significant.

The oral informed consent of the gestants was obtained prior to the start of this investigation. To ensure confidentiality in this study, no sonographer or structure name to identify a health professional was mentioned on a data collection sheet. The data will be used exclusively to make recommendations for the harmonization of the practice for the benefit of pregnant women. We also got the approval of the Ethics Committee on Research.

\section{Results}

\subsection{Frequency}

During the study period, we recorded 34 cases of trophoblastic diseases. At the same time 3560 patients were received in obstetrics, a frequency of 9.5 trophoblastic diseases per 1000 pregnancies. The distribution of GTD cases is presented in Table 1.

\subsection{Description of the Hydatiform Mole Group}

\section{- Clinical aspects}

The average age of the patients was 35 years with extremes of 22 and 52 years. The 30 to 40 age group was in the majority and represented $53 \%$ of the workforce. The average number of gestures was 3 and the average parity was 2.6 patients out of 30 had at least a history of spontaneous miscarriage (20\%) and 5 patients (16.67\%) had a history of at least one abortion (abortion). only one patient in this group had a history of molar pregnancy. The mean gestational age at diagnosis was 11 years with extremes of 4 and 25 years. Clinically, 4 patients (13.33\%) had exaggerated signs of pregnancy and 25 patients (83.33\%) had metrorrhagia. We did not find any signs of preeclampsia or hyperthyroidism in our series. Physical examination revealed a uterus larger than gestational age in 17 patients $(56.67 \%)$ of cases. Eight patients were asymptomatic $(26.67 \%)$ of cases. The initial mean $\beta$-GCH was $453747.8 \mathrm{IU} / 1$ with extremes of $5903 \mathrm{IU} / \mathrm{l}$ and $1,890,000 \mathrm{IU} / \mathrm{l}$

\section{- Ultrasound data}

Ultrasound was used to evoke the diagnosis in 23 patients, $76.67 \%$ of the cases.

\section{$\checkmark$ Complete moles}

Ultrasound identified 10 complete mole cases. Histological examination was consistent in all 10 cases. Ultrasound contributed to the diagnosis in $100 \%$ of cases. The ultrasound aspects were those of an enlarged uterus containing intravesicular multi-vesicular images without embryos or gestational sac (Figure 1 and Figure 2). A unilateral ovarian cyst was found in 6 patients. 
Table 1. Distribution of patients according to the type of GTD.

\begin{tabular}{ccc}
\hline $\begin{array}{c}\text { Type of gestational } \\
\text { trophoblastic disease }\end{array}$ & Number & Details \\
\hline Hydatiform moles & 30 & $\begin{array}{c}\text { complete mole: } 10 \text { cases } \\
\text { partial mole: } 20 \text { cases }\end{array}$ \\
Persistent trophoblastic tumours & 4 & $\begin{array}{c}\text { invasive mole: } 3 \text { cases } \\
\text { choriocarcinoma: } 1 \text { case }\end{array}$ \\
Total & 34 & \\
\hline
\end{tabular}

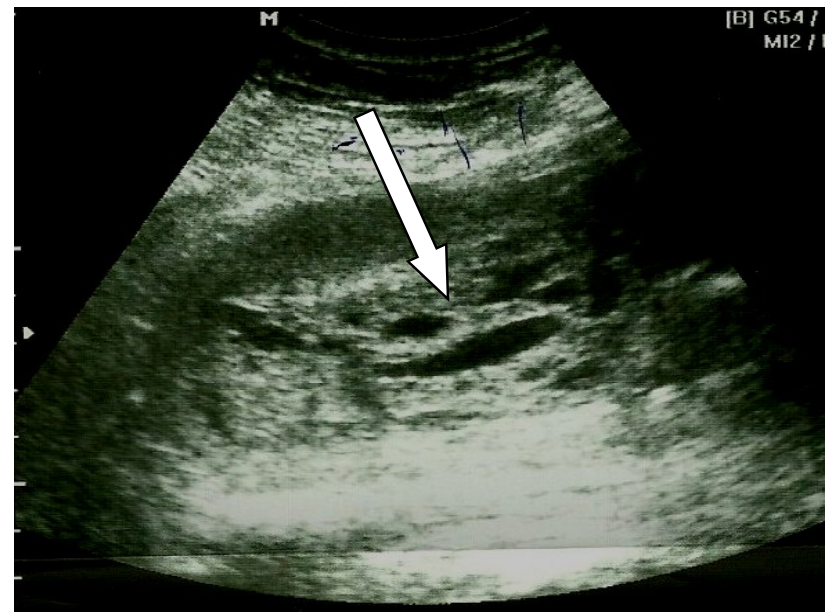

Figure 1. Complete mole: multivesicular aspect (arrow) with augmentation of the uterine cavity without embryo or gestational sac.

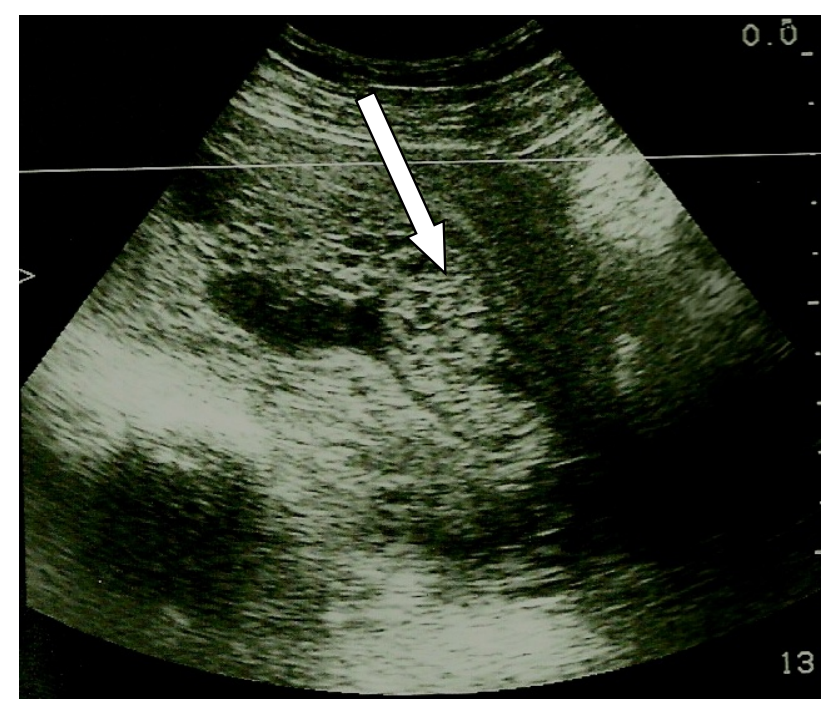

Figure 2. Complete mole: multivesicular appearance with gestational sac without embryo.

\section{$\checkmark$ Partial moles}

We handled 20 partial mole cases. Ultrasound identified 5 histologically confirmed cases with a sensitivity of $25 \%$ (Figure 3 ).

The other aspects of the ultrasound were (Figure 4) stopped pregnancy type 


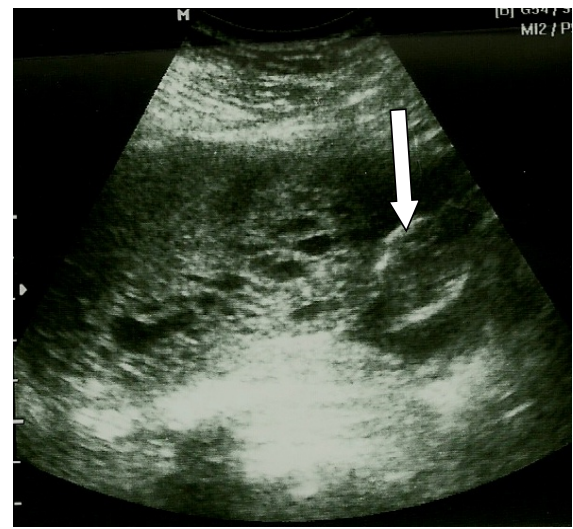

(a)

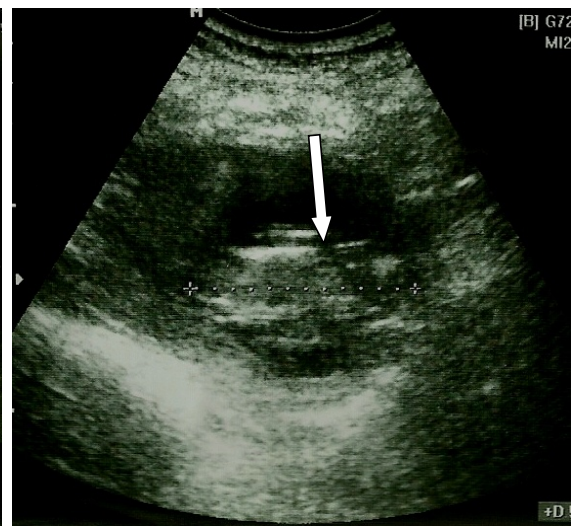

(b)

Figure 3. (a) Typical partial mole appearance. Multivesicular appearance of the trophoblast with presence of an embryo (arrow); (b) Same patient: embryo without cardiac activity (arrow).

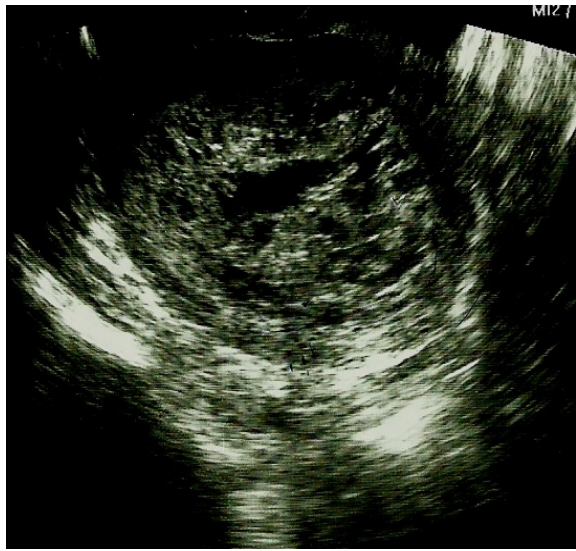

(a)

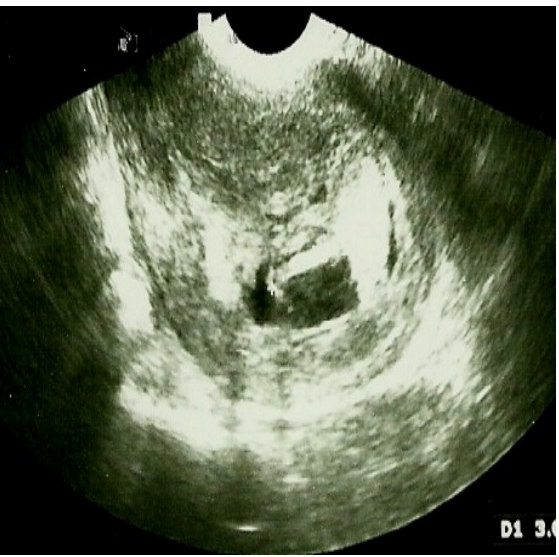

(b)

Figure 4. Atypical aspects of partial mole. (a) Complete mole appearance; (b) Stopped pregnancy appearance.

in 4 cases, latero-uterine image in cocarde with effusion in the cul de sac of Douglas evoking an ectopic pregnancy in 2 cases and an image of hematometry in 1 case.

In addition, the images were rather typical of a complete mole in 8 cases (Table 2). Ultrasound revealed the presence of a cyst in 5 patients, $25 \%$ of the cases.

\section{$\checkmark$ Other imaging examinations}

All patients in the first group were radiographed for chest metastases. No anomalies were found. One patient received a pelvic magnetic resonance imaging (MRI) examination because the ultrasound scan suspected myometrial invasion. The MRI didn't confirm this invasion.

\section{- Treatments received}

All patients in the first group received manual intrauterine aspiration under ultrasound control. Two patients received a red blood cell transfusion during a hemorrhagic molar abortion. One patient in this group received anti D serum 
Table 2. Ultrasound aspects of partial moles.

\begin{tabular}{cc}
\hline Ultrasound aspects & Number \\
\hline $\begin{array}{c}\text { Complete mole: image in snowfall without embryo } \\
\text { Partial mole: multivesicular intrauterine images of the trophoblast with the } \\
\text { presence of gestational sac and/or embryo }\end{array}$ & 8 \\
Appearance of stopped pregnancy: embryo without cardiac activity & 4 \\
Latero-uterine image in a cockade with effusion in the cul de sac of Douglas \\
$\quad \begin{array}{c}\text { (ectopic pregnancy) } \\
\text { Heterogeneous hematometry images } \\
\text { Total }\end{array}$
\end{tabular}

and a hysterectomy was performed in 2 patients 47 and 52 years of age who no longer had a desire for procreation. A second aspiration was necessary in 11 cases $(55 \%)$. During the systematic ultrasound inspection, they presented heterogeneous images with an average diameter of $24.7 \mathrm{~mm}$ in favour of retaining molar debris. Four of the 11 patients had a reactivation of GCH levels.

\section{- Evolution}

The average turnaround time for $\beta \mathrm{GCH}$ was 6.5 weeks. The average length of hospital stay was 7 days. All patients had a favorable outcome.

\subsection{Description of the Group of Persistent Trophoblastic Tumours (PTT)}

\subsubsection{Invasive Mole Subgroup}

\section{- Patients characteristics}

The characteristics of the patients with invasive moles are presented in Table 3.

All patients had a history of abortion. Symptomatology was dominated by metrorrhagia and in all patients the uterus was larger than gestational age. No signs of sympathetic pregnancy were found in any of the 3 patients, nor were there any signs of pre-eclampsia or hyperthyroidism. The average rate of $\beta \mathrm{GCH}$ in these patients was $355,125 \mathrm{IU} / \mathrm{l}$ with extremes of $150,000 \mathrm{IU} / \mathrm{l}$ and 543,000 IU/l.

\section{- Ultrasound data}

For the 3 cases of invasive mole, pelvic ultrasound revealed heterogeneous intrauterine multi-vesicular images that evoked the diagnosis of complete mole. For one of the patients, case 2, ultrasound revealed multivesicular intrauterine images invading the myometrium with a $5 \mathrm{~mm}$ safety wall (Figure 5). For the other two cases, the diagnosis of persistent trophoblastic disease was based on the re-ascension of the rate of $\beta \mathrm{GCH}$ on three successive dosages. At the ultrasound check the uterus was empty; it did not reveal any signs of local extension for these 2 cases. The Doppler was not used in our series. In all the 3 cases, an abdominal-pelvic ultrasound did not show any image of pelvic invasion or liver metastases. 
Table 3. Characteristics of patients with invasive moles.

\begin{tabular}{cccccc}
\hline $\begin{array}{c}\text { Case } \\
\text { number }\end{array}$ & Ages & Miscarriage & $\begin{array}{c}\text { GA at the time of } \\
\text { diagnosis (GA) }\end{array}$ & $\begin{array}{c}\text { Suspicion of } \\
\text { ultrasound }\end{array}$ & $\begin{array}{c}\text { Histological } \\
\text { diagnosis }\end{array}$ \\
\hline 1 & 17 & 1 & 9 & yes & confirmed \\
2 & 31 & 3 & 8 & no & confirmed \\
3 & 46 & 1 & 12 & yes & confirmed \\
\hline
\end{tabular}

GA: Gestational Age.

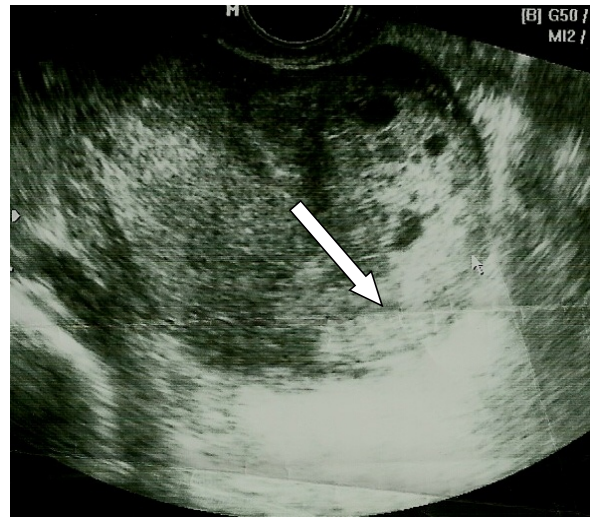

(a)

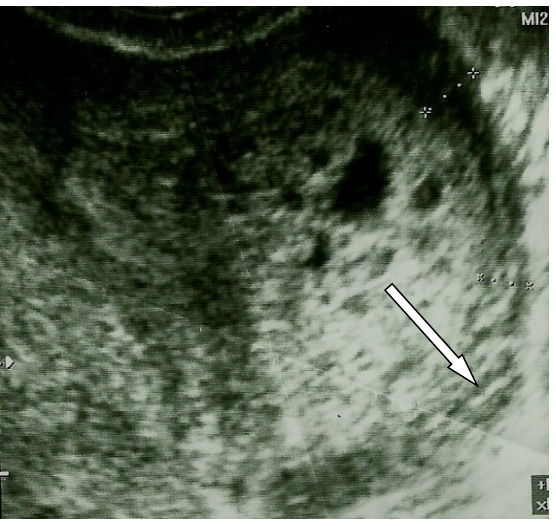

(b)

Figure 5. Ultrasound aspect of an invasive mole with the invasion of the myometrium.

\section{- Other imaging examinations}

All patients were given a chest X-ray. We have not objectified any image in favour of pulmonary metastases. The Case $\# 2$ received a pelvic MRI (Figure 6). Indeed, this patient presented a re-ascension of the rate of $\beta \mathrm{GCH}$ with ultrasound images of myometrial invasion. The MRI confirmed the diagnosis, showing an expansive process of the uterine dome of $5 \times 6 \times 8 \mathrm{~mm}$ with left anterolateral extension whose morphology and MRI signal were compatible with the diagnosis of persistent mole.

\section{- Treatments received}

All patients received monochemotherapy. A hysterectomy was performed in case 3; and uterine artery embolization in case 2 . All patients had a favourable outcome.

\subsubsection{Choriocarcinoma Subgroup}

We've taken over a case of choriocarcinoma. This was a 29 year old patient who had 3 full term pregnancies with a history of molar pregnancy in the year prior to diagnosis. She had been out of sight. The circumstances of the diagnosis were a cough with hemoptoic sputum, weight loss and altered general condition. On ultrasound, we found an enlarged uterus measuring $110 \mathrm{~mm} \times 63 \mathrm{~mm}$ with a poorly limited intracavitary heterogeneous fundic image measuring $56 \mathrm{~mm} \times 42$ $\mathrm{mm}$. There was no sign of local invasion. Abdominal ultrasound did not reveal liver metastases. Chest X-rays and chest scans showed metastases in both pulmonary fields. The initial level of $\beta \mathrm{GCH}$ in this patient was $168,721 \mathrm{IU} / \mathrm{l}$. 


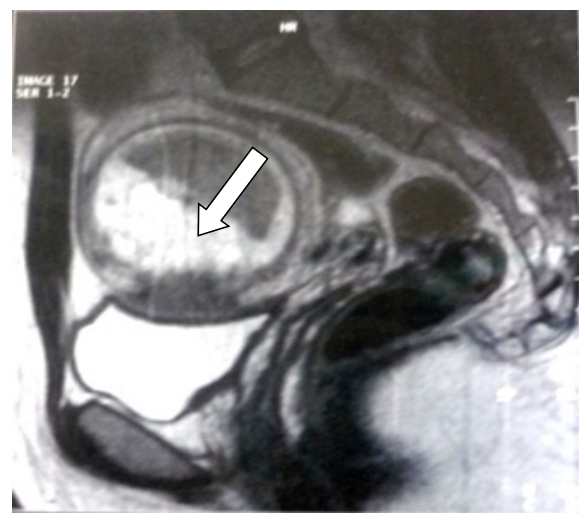

(a)

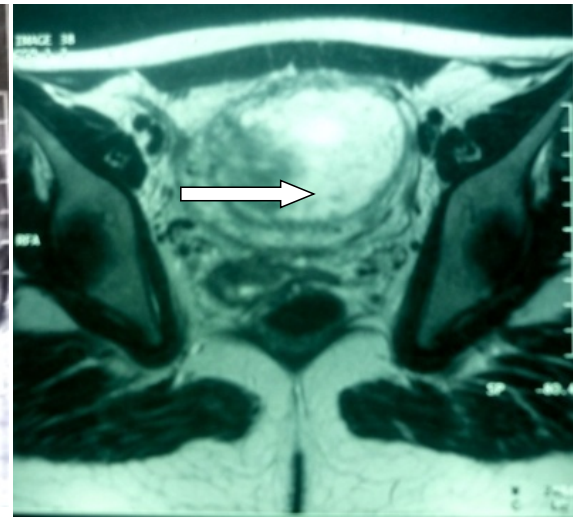

(b)

Figure 6. Invasive mole MRI images: myometrial invasion (arrow) in the same patient as Figure 5: (a) Sagittal section; (b) Cross section.

Anatomopathological examination was not performed with histological confirmation. The patient received multidrug therapy.

\section{Discussion}

\subsection{Clinical Aspects of GTD}

The first quarter metrorrhagia was the main circumstance of GTD discovery in our series (88.33\%) of cases. This has been reported by several authors [5] [6] [7] [8] [9] with frequencies ranging from $75.86 \%$ for Chelli [8] to $95.5 \%$ for Boufettal [2]. The metrorrhagia was associated with exaggerated sympathetic signs of pregnancy in $13 \%$ of cases. Kabouze [10] and Boufettal [2] reported cases of exaggerated signs of pregnancy in $12 \%$ and $18.5 \%$ of cases, respectively. As for the increase in uterine size relative to gestational age, the rate in our series was $56.67 \%$ of the higher rates than ours were reported by Boufettal [2] and Kabouze [10] which are $85 \%$ and $87.5 \%$ respectively.

\subsection{Ultrasound Aspects of GTD}

The value of ultrasound is clearly established in the early diagnosis of GTD. In the first trimester, transabdominal ultrasound or the use of high-frequency vaginal catheters and Doppler techniques allows for the earlier and earlier diagnosis of GTD [8].

\section{- Complete hydatiform moles}

Transabdominal first trimester ultrasound most often shows an enlarged uterus containing a relatively echogenic intracavitary mass sometimes surrounded by a gestational sac [11] [12]. This aspect, although not specific, makes it possible to evoke diagnosis in a clinical context and characteristic biological anomalies. Endovaginal ultrasound allows, when performed, to better specify the multivesicular aspect of the mass and to detect a possible invasion of the myometrium [4] [12]. The same anomalies are observed in the second trimester but they become more voluminous and better visible [4] [11] [12] [13] [14] [15]. The 
absence of an amniotic cavity and embryo, with a uterine cavity dilated by multivesicular hypoechoicular images, often evokes the diagnosis, especially if bilateral ovarian cysts are associated [4] [11] [12] [13] [14] [15].

\section{- Partial hydatiform moles}

Ultrasound is less efficient and the distinction between partial and complete mole can be very difficult [3] [5] [8]. In case of partial mole, there is no typical appearance and several ultrasound aspects may be seen. According to Chelli [8] the ultrasound diagnosis is based on the following elements:

- presence of a placenta that is larger and thicker than a pregnancy of the same term would like and, in some places, has a molar appearance, i.e. multiple cysts;

- presence of an empty gestational sac or one containing amorphous echoes corresponding to a macerated fetus;

○ pregnancy is usually terminated;

- When a well-formed or live fetus is observed, there is frequently intrauterine growth retardation;

- Sometimes it shows microvesicles difficult to distinguish from the focal hydropic degeneration of the villi of a dead egg [2].

However, when ultrasound shows cysts dispersed in the placenta and the diameter of the gestational sac is increased, the predictive diagnosis of a partial mole is estimated at $90 \%$ [16].

\section{- Persistent trophoblastic tumors(PTT)}

Persistent trophoblastic tumors have a high ultrasound polymorphism. Diouf and cervix [13] in a series of 13 cases finds the following ultrasound aspects:

○ a "gap" type with the association of rounded, regular gaps;

- a heterogeneous tissue "hyperdense" type, but without posterior shadow cone;

- a "swampy" type with wide anechoic beaches separated by more or less thick partitions with irregular vegetation;

- a "mite" type has small rounded gaps not exceeding 3 to $5 \mathrm{~mm}$ in a more echogenic and heterogeneous structure.

According to Diouf [13], the ultrasound aspects of gestational trophoblastic tumors are therefore not specific and may lead to discussion of other diagnoses such as trophoblastic retention, endometrial cancer, myoma, hydatidiform mole, and uterine sarcoma. On the other hand, in our series, the ultrasound aspect of the 4 TTG cases evoked a hydatiform mole in 3 cases and a heterogeneous non-specific image in one case. Despite the polymorphism of the ultrasound aspects of gestational trophoblastic tumors, most authors agree on the almost constant presence of ultrasound signs suggestive of aggressiveness and the clinical context which suggest the presence of a gestational trophoblastic tumor. It is a question of reaching several tunics without respect for their architecture, irregular limits, heterogeneous character with hyperdense zones [9] [13]. The association of vegetation or thick partitions has also been described [13]. 


\subsection{The Contribution of Ultrasound in the Diagnosis of Hydatiform Moles}

The current practice of complementary examinations (pelvic ultrasound and dosage of $\beta \mathrm{GCH}$ ) has allowed an early diagnosis of GTD. Indeed, systematic first trimester ultrasound was the circumstance of discovery in $26.67 \%$ of cases in completely asymptomatic patients. Before the advent of ultrasound, the diagnosis was essentially based on the dosage of $\beta \mathrm{GCH}$ plasma and urinary. Currently, thanks to the widespread use of ultrasound in the first trimester, molar pregnancies are diagnosed earlier. The mean gestational age at diagnosis was 11GA in our series. This average age is respectively $8.7 \mathrm{GA}, 9.25$ and $10 \mathrm{GA}$ in the referral centres in the United States, France and England [14]-[19].

In our study, ultrasound contributed to the diagnosis of hydatidiform mole in $76.67 \%$ with a clear predominance for complete mole. Boufettal [2] and Chelli [8] reported similar performances of $77.3 \%$ and $75.86 \%$ respectively. Literature data vary between $34 \%$ and $82 \%$ [4]. These authors justify the high sensitivity rates (between $80 \%$ and $90 \%$ ) reported in other series by the fact that these studies were carried out in referral centres specialising in GTD with operators used to this type of pathology. In all cases, the quantitative assay of $\beta \mathrm{GCH}$ is useful to confirm the diagnosis associated with clinical data, histology and imaging. In view of the diagnostic difficulties in the case of hydatidiform mole, it is recommended that all products of conception obtained after medical or surgical evacuation of a stopped pregnancy or spontaneous miscarriage give rise to a histological examination. In the absence of available aspiration product, remote serum GCH determination of this type of pregnancy is recommended to ensure its normalization [10].

The contribution of ultrasound in complete mole diagnosis is excellent [8]. It is $100 \%$ in our series. This is reported by several authors [20] [21] [22]; this is 96.15\% for Chelliand al [8]. A retrospective study by Lindholm and Flamm [23] reported that $16 \%$ of complete hydatidiform mole cases cannot be diagnosed on ultrasound. Indeed, according to some authors [24] [25] [26], ultrasound images of complete moles are less typical, which can lead to confusion with a stopped pregnancy retained, an enlarged endometrium especially in case of young molar pregnancy.

In our series, the contribution of ultrasound in partial mole diagnosis was $25 \%$. Similar rates are observed by other authors such as Chelliand al [8] who find a sensitivity of $28 \%$ and in the series of several specialized centers with a sensitivity varying between $17 \%$ for Lindholm [23] and 29\% for Flower [19]. Some others had reported in a study of 104 molar pregnancies that histologically confirmed that ultrasound images were suggestive of partial mole in only $8.65 \%$ of cases [26]. Nevertheless, it is recognized that the sensitivity of ultrasound to partial mole increases with gestational age. Kirk and al [12] found sensitivity at $44 \%$ between 13 and $14 \mathrm{SA}+6$ days versus $13 \%$ between 7 and $12 \mathrm{GA}+6$ days. In our series, the mean gestational age at diagnosis was $11 \mathrm{GA}$. 
Despite their great polymorphism, the particularities of GTD give some authors an interest in ultrasound for the diagnosis of choriocarcinoma [7] [19] [20]. For Cheng [20], the sensitivity of ultrasound in the diagnosis of gestational trophoblastic tumors would reach $92.3 \%$.

For several authors, ultrasound is also used to evaluate myometrial extension and invasion [27] [28]. The ultrasound study can be completed by Doppler. They all agree that choriocarcinoma is hypervascular. The identification of hypervascularization is an additional diagnostic argument [28]. Concerning the pelvic extension assessment, these authors [27] report a good correlation between vaginal ultrasound and magnetic resonance imaging (MRI) for the assessment of myometrial extension. In our series, ultrasound revealed myometrial invasion in one case with good correlation with MRI.

Doppler has several interests in the management of trophoblastic diseases [26] [27] [28]. On the diagnostic level, it helps to recognize malignant gestational trophoblastic disease which would have a higher resistance index than in the case of hydatidiform mole [29]. Its interest would also be prognostic since according to Liang [28], the lower the pulsatility index, the worse the prognosis would be because it is associated with a high risk of observing chemo resistance. We didn't use Doppler in our series. These aspects would deserve to be studied in more important series by prospective studies.

\section{Conclusion}

This short series shows the central role of ultrasound in the diagnosis and follow-up of gestational trophoblastic diseases. Indeed, the sensitivity of ultrasound is excellent in the early diagnosis of complete moles. In the case of partial moles, this sensitivity is less important; however, ultrasound coupled with $\beta \mathrm{GCH}$ kinetics allows in most cases to establish an early diagnosis of partial moles. It should nevertheless be pointed out that the systematic anatomopathological examination of any expulsion product remains the gold standard diagnosis. Ultrasonography also remains an examination of choice for the diagnosis of gestational trophoblastic tumors despite their great polymorphism. Ultrasound is also involved in staging the pelvic localization process. The place of ultrasound in prognostic evaluation and treatment monitoring deserves to be studied by more important series

\section{Conflicts of Interest}

The authors declare no conflicts of interest regarding the publication of this paper.

\section{References}

[1] Koné, B., Millogo, F.T. and Lankoandé, J. (1998) les maladies trophoblastiques gestationnelles en milieu africain. Description cliniques, biologique, anatomopathologique et difficultés thérapeutiques. Revue du révérendpère de gynécologie obstétrique, 93, 428-432. 
[2] Boufettal, H., et al. (2011) Les môles hydatiformes complètes au Maroc: étude épidémiologique et clinique. Journal de Gynécologie Obstétrique et Biologie de la Reproduction, 40, 419-429. https://doi.org/10.1016/j.jgyn.2011.02.008

[3] Green, C.L., Angtuaco, T.L. and Shah, H.R. (1996) Gestational trophoblastic desease: un spectre de diagnostic radiologique. Radiographie, 16, 1371-1384.

https://doi.org/10.1148/radiographics.16.6.8946542

[4] Jacob, P.A., Hunt, P.A., Matsura, J. and Wilson, C.C. (1984) Mole hydatiforme complète et partielle à Hawaii: cytogénétique. Morphologie et épidémiologie, 89, 258-266.

[5] Boussen, H., Ben Zineb, N. and Mourali, M. (2001) Les maladies trophoblastiques gestationnelles. Etat des lieux en Tunisie. Journal de Gynécologie Obstétrique et Biologie de la Reproduction, 30, 288.

[6] Jauniaux, E. and Nicholaides, K.H. (1997) Échographie précoce en obtétrique et gynécologie. Journal de gynécologie obstétriqueet de biologie de la reproduction, $\mathbf{9}$, 17-21.

[7] Aboud, P., brohet, A., Mansour, G., et al. (2005) Maladies trophoblastiques gestationnelles. Etude rétrospective de 1997 à 2003. Journal de Gynécologie Obstétrique et Biologie de la Reproduction, 34, 148-153.

[8] Chelli, D., Dimassi, K., Bouaziz, M., Ghaffari, C., Zouaoui, B., Sfar, E., Chelli, H. and Chennoufi, M.B. (2008) Imagerie de maladies trophoblastiques gestationnelles. Journal de Gynécologie Obstétrique et Biologie de la Reproduction, 37, 559-567. https://doi.org/10.1016/j.jgyn.2008.06.003

[9] Coullin, P. (2005) Des andro-et parthégénotes humains (môle hydatiforme et tératomes ovariens) au cancer. Gynécologie Obstétrique \& Fertilité, 30, 42-49.

[10] Khabouze, S., Erchidi, I.E., Bouchikhi, C., Chahtane, A. and Chaoui, A. (2002) les maladies gestationnelles trophoblastiques à propos de 105 cas. Gynécologie Obstétrique \& Fertilité, 30, 42-49. https://doi.org/10.1016/S1297-9589(01)00256-9

[11] Benson, C.B., Genest, D.R., Bernstein, M.R., Soto-wright, V., Golstein, D.P. and Berkowitz, R.S. (2000) Aspect échographique des grains de beauté hydatiformes complets du premier trimestre. Ultrasound in Obstetrics \& Gynecology, 16, 188-191. https://doi.org/10.1046/j.1469-0705.2000.00201.x

[12] Kirk, E., Papageoghiou, A.T., Condous, G., Bottomley, C. and Bourne, T. (2007) The Accuracy of First Trimester Ultrasound in the Diagnosis of Hydatiform Mole. Ultrasound in Obstetrics \& Gynecology, 29, 70-75. https://doi.org/10.1002/uog.3875

[13] Diouf, A., Cissé, M.L., Laico, A., Ndiaye, D., Moreau, M.C. and Diadhiou, F. (2005) Aspects échographiques du choriocarcinome gestationnel. Résultats préliminaires à propos 13 cas. Journal of Radiology, 86, 469-473. https://doi.org/10.1016/S0221-0363(05)81391-5

[14] Drake, R.D., Rao, G., McIntire, D., Miller, D.S. and Schorge, J.O. (2009) Gestational Trophoblastic Disease among Hispanic Women: A 21-Year Hospital-Based Study. Gynecologic Oncology, 103, 81-86. https://doi.org/10.1016/j.ygyno.2006.01.042

[15] Kohorn, E.I. (2001) Le nouveau système FIGO 2000 d'évaluation de la stadification et des facteurs de risque pour les maladies trophoblastiques gestationnelles: description et évaluation critique. International Journal of Gynecological Cancer, 11, 73-77. https://doi.org/10.1046/j.1525-1438.2001.011001073.x

[16] Dreyfus, M., Tissier, I. and Philippe, E. (2005) Les maladies trophoblastiques gestationnelles. Classification, épidémiologie et base génétiques. Journal de Gynécologie Obstétrique et Biologie de la Reproduction, 34, 148-153. 
https://doi.org/10.1016/S0368-2315(05)82706-1

[17] Aloui, F. (2005-2006) Les Maladies trophoblastiques gestationnelles: Etude analytique à propos de 65 cas. Faculté de Médecine de Tunis.

[18] Allena, S.D., Lima, A.K., Seckl, M.J., Blunta, D.M. and Mitchell, A.W. (2006) Radiologie de la néoplasie trophoblastique gestationnelle. Clinical Radiology, 61, 301-313. https://doi.org/10.1016/j.crad.2005.12.003

[19] Flower, D.J., Lyndsay, I., Seckl, M.J. and Sebire, N.J. (2006) Diagnostic échographique de routine avant évacuation d'une taupe hydatiforme: Expérience de plus de 1000 cas dans un centre de référence régional. Ultrasound in Obstetrics \& Gynecology, 27, 56-60.

[20] Cheng, Y., Jiang, Y. and Zhang, S. (1995) diagnostic par ultrasons de tumeur trophoblastique maligne (analyse de $41 \mathrm{cas}$ ). Acta Academiae Medicinae Sinicae, 17, 453-455.

[21] CNGOF, ANM, SFMP (2010) Recommandations de bonne pratique. Maladies trophoblastiques gestationnelles; diagnostique et prise en charge.

[22] Golfier, F., Labrousse, C., Frappart, L., Mathian, B., Guastalla, J.P., Trillet-Lenoir, V., et al. (2007) Evaluation de la prise en charge des tumeurs trophoblastiques gestationnelles enregistrées au centre de référence de Lyon de 1999 à 2005. Gynécologie Obstétrique \& Fertilité, 35, 205-215.

https://doi.org/10.1016/j.gyobfe.2006.12.023

[23] Lindholm, H. and Flamm, F. (1999) The Diagnostic of Molar Pregnancy by Sonography and Gross Morphology. Acta Obstetricia et Gynecologica Scandinavica, 78 , 6. https://doi.org/10.1080/j.1600-0412.1999.780103.x

[24] Caspi, B., Elchalalal, U., Dgana, R., Ben-Hur, H., Rozenman, D. and Nissim, F. (1991) Invasive Mole and Placental Site Trophoblastic Tumor. Deux Entites de la maladie trophoblastique gestationnelle avec un aspect échographique commun. Journal of Ultrasound in Medicine, 10, 517-519.

https://doi.org/10.7863/jum.1991.10.9.517

[25] Gungor, T., Ekin, M., Dumanli, H. and Gokmen, O. (1998) L'échographie Doppler couleur dans la différenciation précoce de l'hydatiforme molaire bénigne de la maladie trophoblastique maligne gestationnelle. Acta Obstetricia et Gynecologica Scandinavica, 77, 862.

[26] Honigl, W., Reich, O., Ranner, G. and Pickel, H. (1997) Choriocarcinome de l'utérus après une grossesse à terme: Imagerie par échographie Doppler couleur vaginale. Ultraschall in der Medizin, 18, 167-168.

[27] DeBaz, B.P. and Lewis, T.J. (1995) Imagerie de la maladie triphoblastique gestationnelle. Seminars in Oncology, 22, 130-141.

[28] Liang, M.G., Boultbee, J.E., Langley, R., Newland, E.S., Begent, R.H. and Baghawe, K.D. (1992) Évaluation Doppler de la fin de la circulation utérine et du comportement clinique des tumeurs trophoblastiques gestationnelles nécessitant une chimiothérapie. British Journal of Cancer, 66, 883-887.

[29] Kajii, T. and Ohama, K. (1977) Origine androgénique des taupes hydatiformes. Nature, 268-4. 